\title{
In situ end-labelling, light microscopic assessment and ultrastructure of apoptosis in lung carcinoma
}

\author{
E F Gaffney, A J O'Neill, M J Staunton
}

\begin{abstract}
Aims-To compare in situ end-labelling (ISEL) of apoptosis in lung carcinoma with quantitative and semiquantitative light microscopic assessment and ultrastructural observations.

Methods-ISEL of apoptosis was evaluated in 42 lung carcinomas ( 24 squamous cell carcinomas, 12 adenocarcinomas and six small cell carcinomas). Results were correlated semiquantitatively with the extent of apoptosis in haematoxylin and eosin stained sections, with apoptotic indices and with ultrastructural observations (nine cases).

Results-In each tumour type the extent of apoptosis identified by ISEL correlated with that observed on light and electron microscopy. Tumour cells undergoing apoptosis showed either uniform nuclear staining with a surrounding "halo" or peripheral nuclear membrane staining. The latter pattern was more prominent in small cell carcinoma and correlated ultrastructurally with early apoptosis. A variable proportion of apoptotic cells and apoptotic bodies were unlabelled. Necrotic tumour cells were weakly stained but were distinguishable from apoptotic cells.

Conclusions-ISEL, if used in conjunction with standard methods for investigating apoptosis, is a useful adjunct to the investigation of apoptosis in human tumour tissue.
\end{abstract}

(f Clin Pathol 1995;48:1017-1021)

Keywords: In situ end-labelling, apoptosis, lung carcinoma.

Apoptosis is the genetically mediated process whereby individual cells are deleted from normal and diseased tissues. ${ }^{1}$ The methods most widely used to identify apoptosis are light and electron microscopy, ${ }^{2-6}$ flow cytometry, ${ }^{7}$ and agarose gel electrophoresis. ${ }^{8}$ However, because of the small size and typically scattered distribution of apoptotic cells and apoptotic bodies in spontaneous human tumours high magnification objectives are needed for studying apoptosis on routine light microscopy. Recently, the in situ end-labelling (ISEL) technique has been used to identify apoptosis in paraffin wax sections. ${ }^{910}$ The principle of ISEL is that the DNA of apoptotic cells becomes fragmented into regular nucleosome sized units, the overhanging $3^{\prime}-\mathrm{OH}$ ends of which can be identified by the immunohistochemical detection of enzymatically incorporated digoxygenin labelled triphosphates such as dUTP. ${ }^{9-11}$

Although ISEL has been used to identify apoptosis in human tumours, ${ }^{12-14}$ there is very little data correlating ISEL findings with standard light and electron microscopic evaluation of apoptosis in tumours. We therefore examined the use of ISEL in the assessment of apoptosis in lung carcinomas, correlating the findings with semiquantitative and quantitative determination of apoptosis on routine light microscopy and with ultrastructural observations.

\section{Methods}

Formalin fixed, paraffin wax embedded sections from 42 lung carcinomas (24 squamous cell carcinomas, 12 adenocarcinomas and six small cell undifferentiated (oat cell) carcinomas) were studied. All, except three (mediastinal or hilar lymph nodes with metastatic small cell carcinoma), were pneumonectomy or lobectomy specimens.

ISEL was performed using an apoptosis detection kit (Oncor, Gaithersburg, Maryland, USA; supplied by Alpha Laboratories, Eastleigh, Hampshire, UK) according to the manufacturer's instructions with the following exceptions: (1) endogenous peroxidase was blocked using $2 \%$ hydrogen peroxide in methanol for 10 minutes; (2) proteinase $K(40 \mu \mathrm{g}$ / $\mathrm{ml}$ ) was applied to sections in a humidified chamber at $37^{\circ} \mathrm{C}$ for 15 minutes; (3) $35-40 \mu \mathrm{l}$ of working strength $\mathrm{TdT}$ enzyme was added per slide; (4) one drop of anti-digoxygenin peroxidase was added per slide; and (5) sections were stained with 3,3'-diaminobenzidine, for seven minutes, and methyl green (five dips). Sections of testis, containing meiosis induced, double stranded DNA breaks, were used as controls. Apoptosis identified by ISEL was assessed semiquantitatively on a scale of $0-5(0=$ no apoptosis, $1=$ rare apoptotic cells/bodies, $2=$ focal, $3=$ diffuse, not extensive, $4=$ multifocal, $5=$ very extensive).

Apoptotic indices were determined in haematoxylin and eosin stained sections as previously described, avoiding zones of necrosis. ${ }^{6}$ In addition, apoptosis was assessed semiquantitatively using a similar scale $(0-5)$ to that used for the assessment of ISEL.

Nine cases (four squamous cell carcinomas, two adenocarcinomas, three small cell carcinomas) were examined by electron microscopy, specifically to identify and characterise 


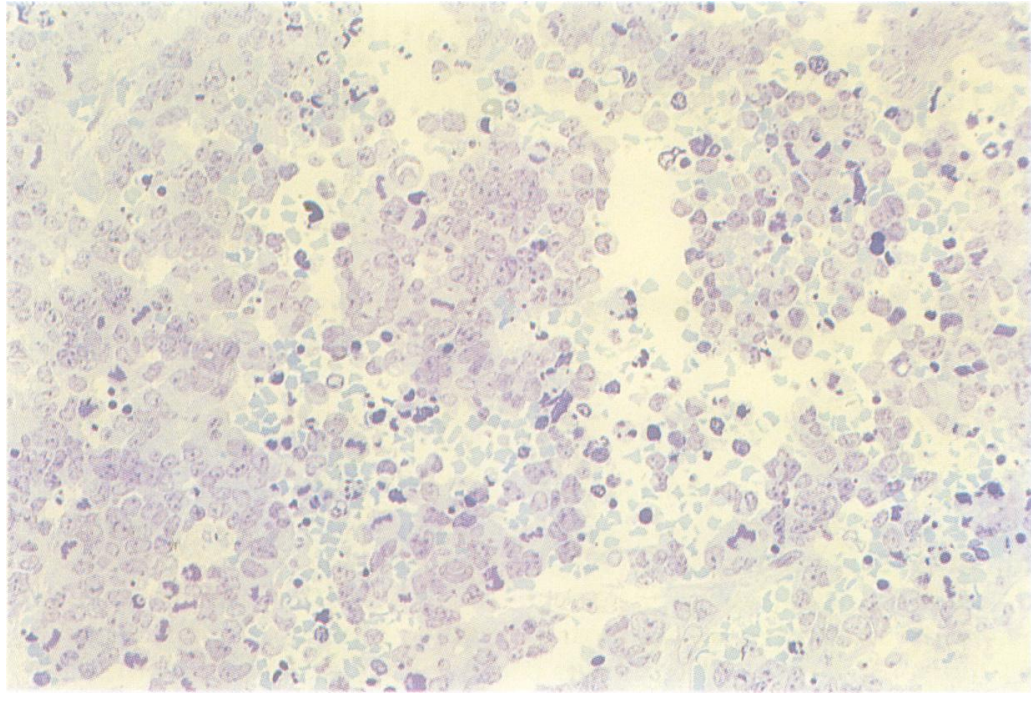

Figure 1 Apoptosis in small cell undifferentiated carcinoma. The nuclear chromatin of apoptotic tumour cells is irregularly condensed or peripheral. Toluidene blue, $\times 400$.

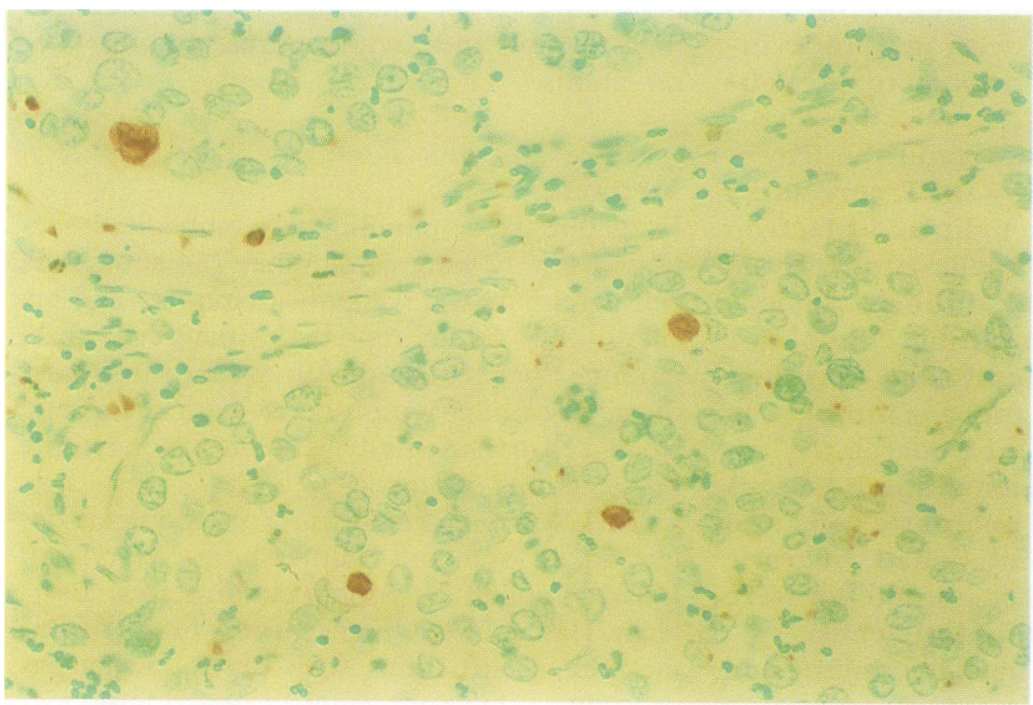

Figure 2 In situ end-labelling of apoptosis in squamous cell carcinoma ( $\times 400)$.

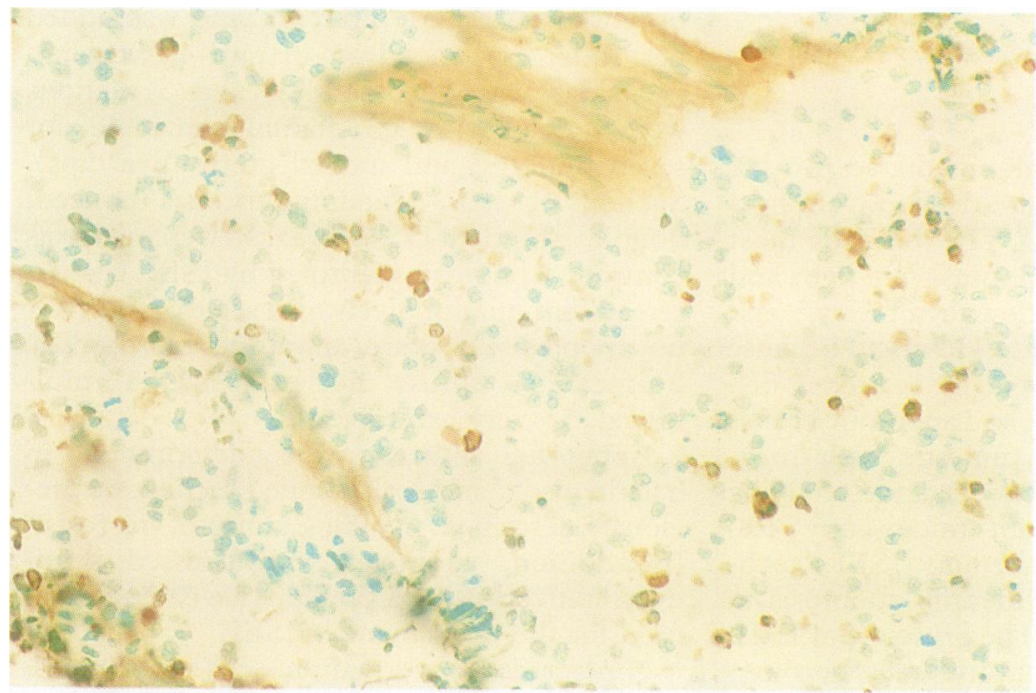

Figure 3 In situ end-labelling of apoptosis in small cell undifferentiated carcinoma. Most apoptotic tumour cells in this field show irregular nuclear membrane staining (see fig 1), but a minority show staining of shrunken nodular chromatin $(\times 400)$. the ultrastructure of apoptosis. Six specimens were fixed initially in $2 \%$ glutaraldehyde. The other three specimens had been fixed initially in $10 \%$ neutral buffered formalin and subsequently placed in $2 \%$ glutaraldehyde. All tissue was post-osmicated and processed for electron microscopy. From resin blocks, $0.5 \mu \mathrm{m}$ semithin sections were cut and stained with toluidene blue for light microscopy. Ultrathin sections from selected blocks were stained with uranayl acetate and lead citrate, and examined in a Hitachi 7100 electron microscope.

\section{Results}

In all three tumour types apoptotic cells and apoptotic bodies were scattered among viable tumour cells and were often also concentrated in the non-viable rim of necrotic zones. Small cell undifferentiated carcinoma had more apoptosis than either squamous cell carcinoma or adenocarcinoma; apoptotic cells, with peripherally beaded or shrunken nodular condensed chromatin, and apoptotic bodies occurred in clusters among viable tumour cells, with no associated inflammatory response. The cytological detail of cells undergoing apoptosis was more clearly seen in semithin toluidene blue sections (fig 1).

On ISEL, squamous cell carcinomas and adenocarcinomas showed moderate to strong staining of the shrunken nuclear chromatin in apoptotic cells. These cells usually had a perinuclear "halo" and often had cell membrane condensation (fig 2). Some apoptotic cells and apoptotic bodies showed enhanced staining of the nuclear membrane with reduced or absent staining of the remainder of the nucleus. Occasional, apparently normal tumour cell nuclei were also labelled. A variable proportion of morphologically identifiable apoptotic cells and apoptotic bodies did not stain.

In small cell carcinomas apoptotic tumour cells predominantly showed an irregular nuclear membrane ISEL pattern (fig 3). This ISEL pattern correlated closely with the morphology of apoptosis seen in toluidene blue (fig 1) and ultrathin sections (see later). Many apoptotic cells and apoptotic bodies were not labelled.

On ISEL, there was also weak cytoplasmic staining of tumour cells that had phagocytosed apoptotic tumour cells or lymphocytes. Macrophages showed cytoplasmic staining and necrotic cells showed homogeneous weak staining that differed from that seen in apoptotic cells (fig 4). In necrotic zones apoptotic cells were seen in the non-viable rim and occasionally mixed with central necrotic tumour cells or polymorphs. Very scattered labelled apoptotic cells were identified within bronchiolar epithelium and in alveolar spaces in areas of bronchopneumonia distal to the tumour.

Apoptotic indices ranged from $0 \cdot 1$ to $5 \cdot 4 \%$ (mean $1.3 \%$ ) for adenocarcinoma, 0.04 to $7.9 \%$ (mean $2.3 \%$ ) for squamous cell carcinoma and 5.4 to $14.0 \%$ (mean $10.9 \%$ ) for small cell carcinoma. Semiquantitative assessment of apoptosis reflected apoptotic indices for each tumour type-for example, most adenocarcinomas had a score of 1 and five of 


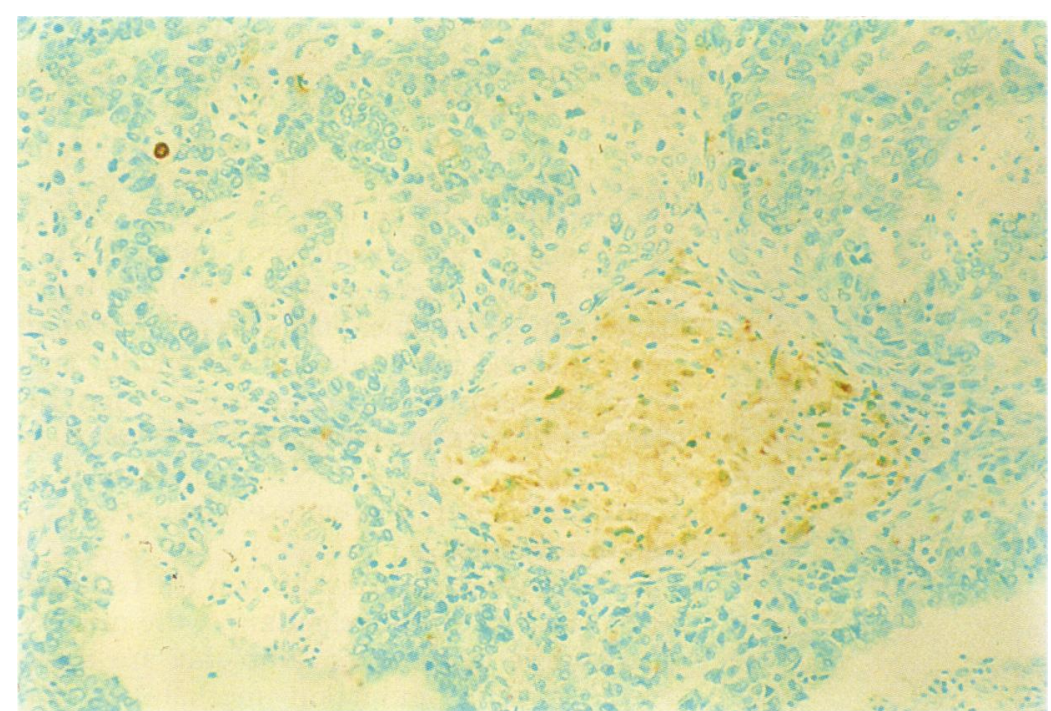

Figure 4 Necrotic tumour cells stain faintly in contrast to an apoptotic tumour cell (top left) in squamous cell carcinoma $(\times 400)$.

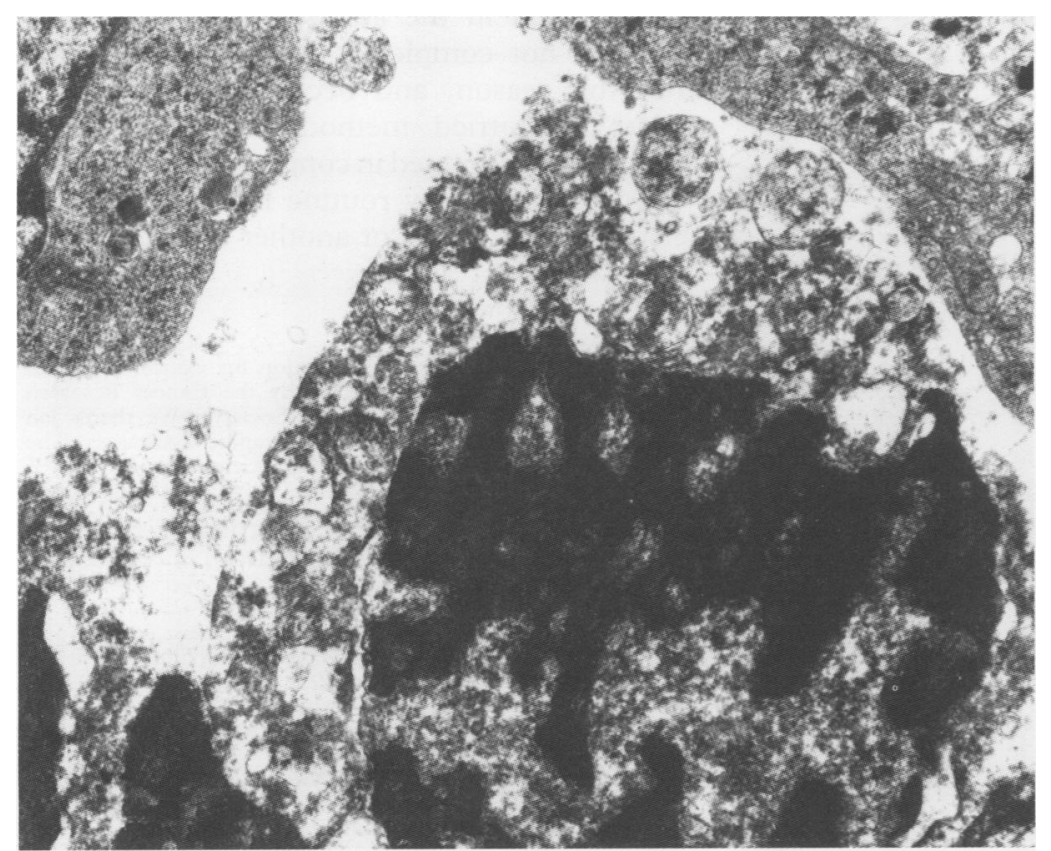

Figure 5 Ultrastructure of apoptosis in small cell carcinoma. The apoptotic tumour cell shows irregular, dense, maze-like subnucleolemmal condensation of nuclear chromatin (original magnification $\times 14000$ ).

six small cell carcinomas had a score of 5 . Semiquantitative apoptosis scores of 2-4 (each based on an entire section) often did not correspond exactly to the apoptotic indices, which were based on the assessment of 10 high power fields only. However, in all tumours a semiquantitative score of 2-4 reflected an intermediate extent of apoptosis, as determined by the apoptotic indices. Semiquantitative ISEL scores were comparable (identical or with a score difference of 1 ) to the semiquantitative assessment of apoptosis in 27 of 34 tumours. Finally, the extent of apoptosis identified in toluidene blue and ultrathin sections correlated with light microscopic and ISEL determinations of apoptosis for the three small cell carcinomas only, because of sampling limitations in the other tumours, which had less apoptosis.
Small cell carcinomas showed the spectrum of ultrastructural cellular alterations associated with apoptosis. In two cases tumour cells showed predominantly early apoptotic features with irregular peripheral subnucleolemmal or maze-like transnuclear condensation of granular osmiphilic chromatin (fig 5). The third case, which had less apoptosis, contained more uniformly osmiphilic apoptotic nuclei, interpreted as representing a later stage of apoptosis (fig 6). Compared with small cell carcinoma there was minimal apoptosis in squamous cell carcinoma or adenocarcinoma. In both adenocarcinoma and squamous cell carcinoma occasional phagocytosed apoptotic bodies and tumour cells exhibiting late apoptotic changes (fig 7) were seen. One adenocarcinoma had rare tumour cells in early apoptosis.

\section{Discussion}

The proportion of tumour cells stained by ISEL and their distribution within the principal lung carcinoma types correlated well with the assessment of apoptosis on light and electron microscopy. The different ISEL patterns observed emphasise the morphological diversity of apoptosis. A variable number of apoptotic cells in each tumour were not labelled by this method, and we cannot exclude the possibility that DNA breaks in certain non-apoptotic tumour cells were also identified by ISEL, as suggested previously. ${ }^{10}$ However, we consider that the great majority of tumour cells identified by ISEL were unquestionably apoptotic, given the close correlation of ISEL results with assessment on light and electron microscopy. On ISEL, apoptotic tumour cells were distinguishable from weakly labelled necrotic cells. Finally, we suggest that cytoplasmic staining observed in macrophages possibly represents staining of DNA that has undergone further enzymatic degradation.

It has been suggested ${ }^{15}$ that peripheral nuclear membrane staining, as illustrated herein, represents early apoptosis. ${ }^{1617}$ Our combined ISEL and ultrastructural findings support this. This was the predominant ISEL pattern seen in small cell carcinoma, although it was also observed to a lesser extent in squamous cell carcinoma and adenocarcinoma. This implies that the majority of apoptotic cells identified by ISEL in small cell carcinoma are in the early stages of apoptosis, clusters of tumour cells having simultaneously undergone apoptosis, as in morphogenesis or in tumour regression. Indeed, a peripheral nuclear staining pattern was also illustrated by Fukasawa et al in regressing myofibromatosis. ${ }^{12}$ Extensive peripheral nuclear labelling may therefore be indicative of particularly widespread apoptosis, but this remains to be examined in greater detail. Other possible explanations are that in small cell carcinoma a different apoptosis inducing stimulus is associated with different apoptosis morphology, that adjacent tumour cells and macrophages effect more rapid clearance of late stage apoptotic cells from the tumour tissue, and that the later stages of 


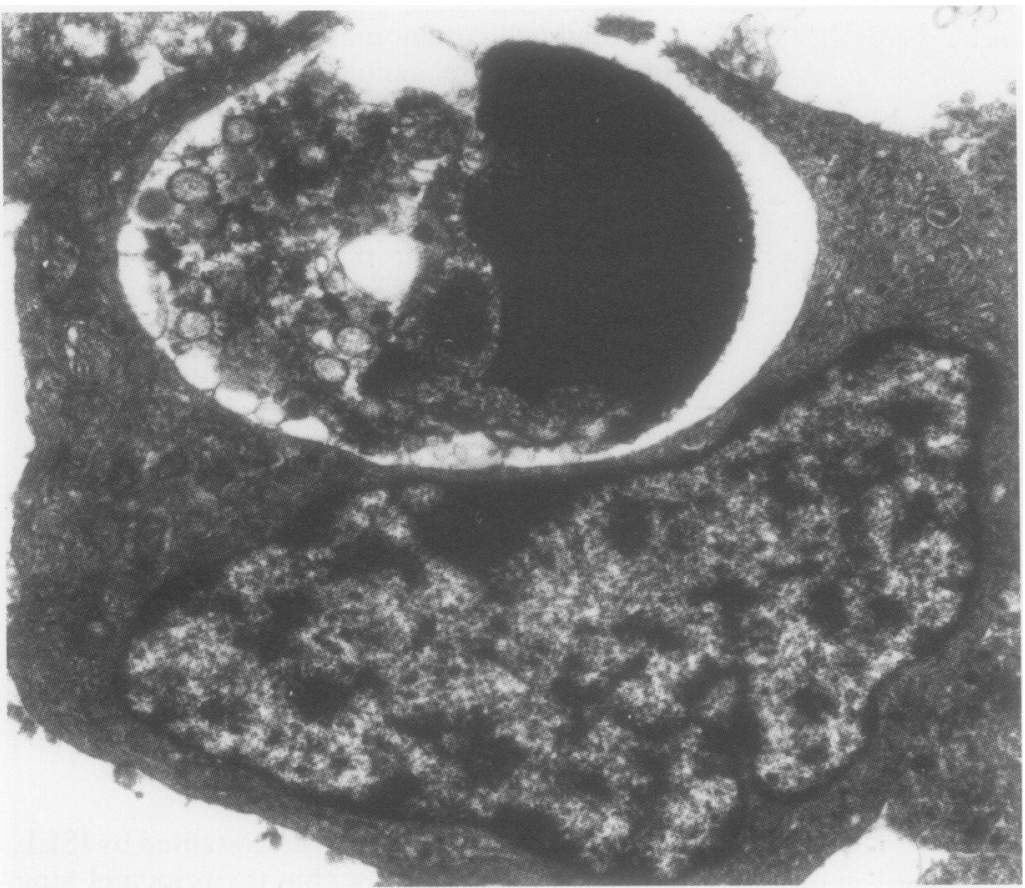

Figure 6 A shrunken apoptotic tumour cell, with dense nuclear chromatin, is engulfed by an adjacent tumour cell in small cell undifferentiated carcinoma (original magnification $\times 12$ 000).

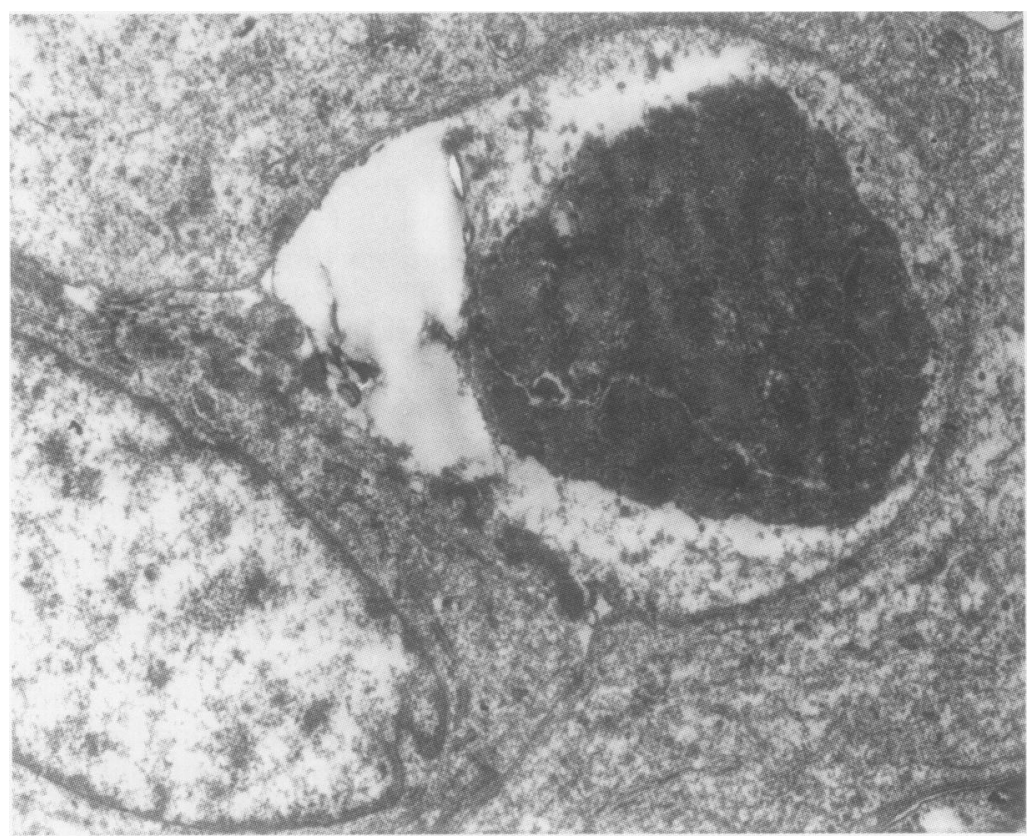

Figure 7 Late stage apoptosis in poorly differentiated squamous cell carcinoma (original magnification $\times 12000$ ). reported without morphological evidence of apoptosis. ${ }^{27}$ DNA breaks alone are not sufficient evidence of apoptosis because they may occur in response to various endogenous or exogenous mutagens. ${ }^{2829}$ It is unclear how DNA breaks in susceptible cells escape normal DNA repair mechanisms and undergo secondary DNA fragmentation. ${ }^{21}$ DNA fragmentation alone does not cause structural collapse and condensation of chromatin, and in certain systems the two processes may be triggered by separate pathways. ${ }^{30}$ It remains to be determined whether DNA fragmentation is a consistent feature of apoptosis in spontaneous human tumours.

In conclusion, we consider that ISEL would facilitate a better understanding of the process of apoptosis in tumours. Not only are there several possible induction mechanisms for apoptosis but there may also be differences in the manner of DNA fragmentation among different tumour types, as reported in certain experimental systems. Like most other techniques used in the assessment of apoptosis, ISEL is not completely sensitive or specific. For this reason, and because it is as yet a relatively untried method, results of ISEL should be interpreted in conjunction with apoptosis assessment by routine light microscopy, electron microscopy or another standard technique. $^{31}$

A J O'Neill holds the Irish Association for Cancer Research Studentship and is also supported by the Cancer Research Advancement Board (Irish Cancer Society). We thank Jan Walker and Anne Mynes for photographic assistance. Th manuscript was typed by Mrs Kathryn Kiely.

1 Wyllie AH. Apoptosis and the regulation of cell numbers in normal and neoplastic tissues: an overview. Cancer Metastasis Rev 1992;11:95-103.

2 Kerr JFR, Wyllie AH, Currie AR. Apoptosis: A basic biological phenomenon with wide-ranging implications in tissue kinetics. Br 7 Cancer 1972;26:239-57.

3 Kerr JFR, Winterford C, Harmon B. Apoptosis: Its significance in cancer and cancer therapy. Cancer 1994;73. 2013-26.

4 Leoncini L, Del Vecchio MT, Megha T, Barbini P, Galien $\mathrm{P}$, Pileri $\mathrm{S}$, et al. Correlations between apoptotic and proliferative indices in malignant non-Hodgkin's lymphomas. Am $\mathcal{F}$ Pathol 1993;142:755-63.

5 Gaffney EF. The extent of apoptosis in different types of high grade prostatic carcinoma. Histopathology 1994;25 269-74.

6 Staunton MJ, Gaffney EF. Tumor type is a determinant of susceptibility to apoptosis. Am f Clin Pathol 1995;103: 300-7

7 Darzynkiewicz A, Bruno S, Del Bino G, Gorczyca W, Hotz MA, Lassota P, et al. Features of apoptotic cells measured by flow cytometry. Cytometry 1992;13:795-808.

8 Wyllie AH. Glucocorticoid-induced thymocyte apoptosis is associated with endogenous endonuclease activation. is associated with endogen

apoptosis are not labelled for technical reasons, such as conformational changes in DNA that render end-labelling sites inaccessible. ${ }^{18}$

Classic morphological apoptosis is associated with internucleosomal DNA fragmentation, often preceded by transient breaks in single or double stranded DNA. ${ }^{19-21}$ The large DNA fragments formed initially are undetectable by standard agarose gel electrophoresis, ${ }^{22-24}$ but stepwise degradation of subsequent 10-40 kilobase fragments into oligonucleosomes produces the distinctive DNA ladder pattern. However, apoptosis has been reported to occur in the absence of DNA fragmentation, with no ladder pattern, ${ }^{22}{ }^{25}$ or with a delayed ladder pattern. ${ }^{26} \mathrm{~A}$ DNA ladder pattern has also been

Gavrieli Y, Sherman Y, Ben-Sasson SA. Identification of programmed cell death in situ via specific labelling of nuclear DNA fragmentation. f Cell Biol 1992;119:493501

10 Ansari B, Coates PJ, Greenstein BD, Hall PA. In situ endlabelling detects DNA strand breaks in apoptosis and other physiological and pathological states. $\mathcal{F}$ Pathol 1993 170:1-8.

11 Wijsman JH, Jonker RR, Keijzer R, Van de Velde $\mathrm{CJH}$ Cornelisse CJ, Van Dierendonck JH. A new method to detect apoptosis in paraffin sections: in situ end-labelling of fragmented DNA. $₹$ Histochem Cytochem 1993;41:7-12.

12 Fukasawa Y, Ishikura $\mathrm{H}$, Takada A, Yokoyama S, Imamura $M$, Yoshiki $T$, et al. Massive apoptosis in infantile myofibromatosis - A putative mechanism of tumor regression. Am f Pathol 1994;144:480-5.

13 Schiffer D, Cavalla P, Chio A, Giordana MT, Marino S, Mauro A, et al. Tumor cell proliferation and apoptosis in medulloblastoma. Acta Neuropathol 1994;87:362-70.

14 Mundle S, Iftikhar A, Shetty V, Alvi S, Dameron S, Gregory $S$, et al. In situ end labelling of DNA to detect apoptotic cell death in a variety of human tumors. Cell Death Differentiation 1994;1:117-22. 
15 Gorczyca W, Gong J, Darzynkiewicz Z. Detection of DNA strand breaks in individual apoptotic cells by the in situ terminal deoxynucleotidyl transferase and nick translation assays. Cancer Res 1993;53:1945-51.

16 Kerr JFR, Searle J, Harmon BV, Bishop CJ. Apoptosis. In: Potten CS, ed. Perspectives on mammalian cell death. Oxford: Oxford University Press 1987:93-128.

17 Sun X-M, Snowden RT, Dinsdale D, Ormerod MG, Cohen GM. Changes in nuclear chromatin precede internucleosomal DNA cleavage in the induction of apoptosis by etoposide. Biochemical Pharmacol 1994;47:187-95.

18 Vologodskii AV, Cozzarelli NR. Supercoiling, knotting, looping and other large-scale conformational properties of DNA. Curr Opin Cell Biol 1994;4:372-5.

19 Wyllie AH, Morris RG, Smith AL, Dunlop D. Chromatin cleavage in apoptosis: association with condensed chromatin morphology and dependence on macromolecular synthesis. $\mathcal{f}$ Pathol 1984;142:67-77.

20 Wyllie, AH. Cell death. Int Rev Cytol 1987;17(Suppl):75585.

21 Kamesaki S, Kamesaki H, Jorgensen TJ, Tanizawa A, Pommier Y, Cossman J. bcl-2 protein inhibits etoposide-induced apoptosis through its effect on events subsequent to topoisomerase II-induced DNA strand breaks and their to topoisomerase II-induced DNA stranc

22 Walker R, Kokileva L, LeBlanc J, Sikorska M. Detection of the initial stages of DNA fragmentation in apoptosis. BioTechniques 1993;15:1032-40.

23 Cohen GM, Sun X-M, Fearnhead H, MacFarlane $M$, Brown DG, Snowden RT, et al. Formation of large molecular weight fragments of DNA is a key committed step of apoptosis in thymocytes. F Immunol 1994;153: 507-16.

24 Sun X-M, Cohen GM. $\mathrm{Mg}^{2+}$-dependent cleavage of DNA into kilobase pair fragments is responsible for the initial degradation of DNA in apoptosis. 7 Biol Chem 1994;269: 14857-60.

25 Cohen GM, Sun X-M, Snowden RT, Dinsdale D, Skilleter DN. Key morphological features of apoptosis may occur in the absence of internucleosomal DNA fragmention. Biochem $\mathcal{F} 1992 ; 286: 331-4$.

26 Zakeri Z, Quaglino D, Latham T, Lockshin RA. Delayed internucleosomal DNA fragmentation in programmed cell internucleosomal DNA fragmen

27 Enright H, Hebbel RP, Nath KA. Internucleosomal cleavage of DNA as the sole criterion for apoptosis may be artefactual. F Lab Clin Med 1994;124:63-8.

28 Phillips JW, Morgan WF. DNA double-strand breaks in mutagenesis. Environ Mol Mutagen 1993;22:214-17.

29 Ames BN, Shigenaga MK, Gold LS. DNA lesions, inducible DNA repair, and cell division: three key factors in mutagenesis and carcinogenesis. Environ Health Perspect 1993; 101(Suppl 5): 35-44.

30 Sun DY, Jiang S, Zheng L-M, Ojcius DM, Young J D-E. Separate metabolic pathways leading to DNA fragmentation and apoptotic chromatin condensation. $\mathcal{f}$ Exp Med 1994;179:559-68.

31 Gold R, Schmied M, Giegerich G, Breitschopf H, Hartung $\mathrm{HP}$, Toyka KV, et al. Differentiation between cellular apoptosis and necrosis by the combined use of in situ tailing and nick translation techniques. Lab Invest 1994; 71:219-25. 